\title{
Developing a Co-Production Strategy to Facilitate the Adoption and Implementation of Evidence- Based Colorectal Cancer Screening Interventions for Rural Health Systems: A Pilot Study
}

Jungyoon Kim ( $\sim$ jungyoon.kim@unmc.edu )

University of Nebraska Medical Center https://orcid.org/0000-0002-2945-2460

Paul Estabrooks

University of Nebraska Medical Center

Alisha Aggarwal

University of Nebraska Medical Center

Analisa McMillan

University of Nebraska Medical Center

Khalid Alshehri

University of Nebraska Medical Center

\section{Research}

Keywords: Electronic blueprint implementation strategy, academic-clinical partnership, colorectal cancer screening; rural primary care; mixed-method

Posted Date: September 29th, 2021

DOI: https://doi.org/10.21203/rs.3.rs-934240/v1

License: (c) (i) This work is licensed under a Creative Commons Attribution 4.0 International License.

Read Full License 


\section{Abstract}

Background: Evidence-based colorectal cancer screening (CRCS) interventions exist, but have not been broadly adopted in rural primary care settings. Participatory adoption and implementation strategies may be promising in closing this gap through a clinical-academic partnership to guide rural practitioners to locate, select, and implement CRCS interventions that align with local context. We developed a prototype strategy adapted from the National Cancer Institute's 'Putting Public Health Evidence in Action' curriculum in collaboration with two rural clinics to facilitate systems change related to CRCS. This paper describes the process of co-development and delivery of a systems-focused strategy to improve adoption, implementation, and sustainability of CRCS interventions.

Methods: We used a bundle of implementation strategies with a core focus on academic-clinical partnership development and Plan-Do-Study-Act cycles to identify clinical partner interests/preferences on delivery methods and content needed to facilitate intervention identification and systems-change processes that improve CRCS rates. Clinic physicians and staff $(n=7)$ at the rural clinics were asked to evaluate the approach based on overall reactions and perceptions of innovation characteristics using 5point Likert scale. After completing the systems-change process, we conducted key-stakeholder interviews $(n=5)$ to assess feasibility and acceptability on content/delivery format and plans for ongoing implementation of CRCS evidence-based interventions (EBIs).

Results: Electronic blueprints for CRCS EBI selection and implementation (8 modules) were developed and followed by an online forum/live-streaming conference to allow for CRCS tailoring. The two clinics used different learning approaches: one completed the modules together while the other completed the modules separately to cover material before a group video conference. Across all modules, participants in both clinics reported positive reactions toward the systems-change modules. Both clinics reported improvements in how they perceived the characteristics of the modules and the participatory approach to tailor selected CRCS EBIs. Through the process both clinics developed a specific EBI implementation plan. Interview participants reported that the approach was feasible and acceptable, and provided suggestions for further improvements on content, delivery, and format of the approach.

Conclusions: The bundle of implementation strategies used were feasible and acceptable in rural primary care practices to facilitate the use of evidence-based approaches to improve CRCS.

\section{Contributions To The Literature}

- Few studies report on the co-production of implementation strategies for evidence-based colorectal cancer screening (CRCS) in rural primary care clinics.

- A bundle of strategies that begin with providing an electronic blueprint to match CRCS EBIs with system resources and infrastructure is feasible and acceptable for small rural primary care clinics.

- This bundle of strategies has potential to improve adoption, implementation, and sustainability of CRCS EBIs. 


\section{Background}

Colorectal cancer screening (CRCS) received an "A" grade from the United States Preventive Services Task Force (USPSTF), the highest-ranking for a preventive care screening (1). According to the USPSTF recommendation, anyone aged between 50 and 75 without symptoms or family history can prevent or detect cancer in earlier stages by performing visual examinations or taking high-sensitive stool tests. Due to recent increasing trend in colorectal cancer (CRC) incidence rate in younger age, the American Cancer Society now recommends regular CRC screening for ages 45 and older. Despite strong evidence, CRCS rates in the US are not optimal. According to a 2020 report, $69 \%$ of US adults between ages 50 and 75 have completed CRC screening as recommended by the national guidelines with a wide range of variations by state (58\% in Wyoming and $77 \%$ in Massachusetts) (2).

Fortunately, the CommunityGuide recommends several CRCS evidence-based interventions (EBIs), including one-on-one client education, small media (e.g., brochures or posters), client reminders, and/or provider assessment and feedback, at multiple levels (3-6). The National Cancer Institute (NCl) also introduced 22 research-tested intervention programs for promoting CRCS, and among those, 8 targeted rural and low-income populations (7). Despite the strong evidence and a wide range of choices of EBls available for CRCS, it is challenging for rural health practitioners to find CRCS EBIs (8), determine the resources and systems changes needed for implementation, and then select and initiate the EBIs that fit best to practice organizations' context $(9,10)$. This is not an inconsequential issue because uncertainty about "fit" can potentially lead to poor outcomes in the implementation and sustainability of EBIs. Uncertainty can also put heavy demands on rural health systems that are chronically overburdened and under-resourced, further increasing concerns about applying resources to strategies that ultimately do not fit within the local system.

It is not surprising that the challenge in EBI adoption and implementation contributes to geographic health disparities. Rural communities experience a higher CRC incidence and mortality and lower CRC screening rates than urban counterparts. Davis et al. (2013) reported that rural patients were less likely to have received a screening recommendation than urban patients $(36.4 \%$ vs. $45.8 \%)$ or less likely to have completed the stool-based test (22.0\% vs. $45.8 \%)$ (11). Cole et al. (2013) found that rural, non-Hispanic Whites have lower predicted CRCS rates than urban, non-Hispanic Whites (44.3\% vs. $49.5 \%)$ (12). This rural-urban gap is exacerbated when combined with racial and ethnic factors and is even larger in states with lower screening rates compared to those with higher screening rates (13).

Due to resource differences between urban and rural clinics, the co-production of implementation strategies to facilitate CRCS EBI uptake is appealing. Co-production is often operationalized in participatory approaches that work to close the gap in CRCS rates between rural and urban areas. A participatory approach is typically an ongoing, engaged clinical-academic partnership to facilitate the movement of EBIs from research to practice, create sustainable systems change, and address health disparities (14-16). The role of academic members in the partnership is to increase resources by engaging as knowledge brokers that can summarize existing EBIs, provide support for health systems to 
prioritize across available EBls, and gather and report on system processes and outcomes that can inform adaptation and sustainability (14). Participatory approaches also tend to bundle implementation strategies such as developing a facilitated blueprint for EBI implementation, academic-clinical partnership development, and plan-do-study-act cycles to identify clinical partner interests and preferences on delivery methods and content needed to facilitate intervention identification and systemschange processes that improve EBI adoption implementation and sustainability (17). A guided, lowburden, participatory approach can help rural healthcare providers locate, select, and implement the EBIs that best align with their needs and capacities (18-20) and determine system changes necessary for implementation.

In this paper, we describe the development of a participatory approach to identify CRCS EBIs, facilitate systems changes to support implementation, and conduct ongoing training and technical support, which was adapted using the Cancer Prevention and Control Research Network, "Putting Public Health Evidence in Action (PPHEA)" (21). PPHEA was designed to use a participatory facilitation approach and has demonstrated its feasibility and effectiveness in promoting physical activity and obesity prevention, afterschool programs, and cancer prevention and education (22-26). While these applications of the PPHEA show promise, initial applications used a relatively intensive face-to-face process that is unlikely to fit in busy, rural primary care practices. To further increase the acceptability and feasibility of this approach for rural health practitioners, we identified the need to develop alternative delivery methods for the PPHEA program for rural healthcare providers. The program content was also adapted to align specifically with CRCS EBIs and needed systems changes. To address these issues, our team developed a prototype of a bundle of implementation strategies that balanced training on EBI implementation with guidance on system changes to support EBI success. In this study, we described the process of developing and delivering this bundle of implementation strategies and tested the feasibility and acceptability of this approach with the pilot sites.

\section{Methods}

\section{Study setting}

The study was conducted with a rural accountable care organization (ACO) located in a city with less than 25,000 residents. Primary care providers and health systems can play an essential role in guiding and recommending CRCS for rural residents (27). The participating ACO was formed in 2016 and consisted of a 116-bed regional referral center and six primary care clinics. All six ACO clinics have adopted an electronic medical records (EMR) system, but they have varying degrees of implementation and different vendors. Since 2018, the ACO has participated in a performance-based payment program with Blue Cross Blue Shield (BCBS) Nebraska. This program rewards providers with group bonuses for the quality of care they give to BCBS members. The ACO receives a quarterly "feedback report" from BCBS on selected measures, including CRCS, and earns points based on performance compared with quality benchmark scores. 
Among the six ACO clinics, the two clinics served as pilot sites for this study. Clinic A provides essential primary care services to the community through 6 providers (3 physicians, 1 APRN, and 2 PAs). Additional staff included three receptionists, 1 MA, 5 LPNs, 2 RNs, 1 CNA, two lab/radiology technicians, one medical records clerk, and two office/billing managers. Clinic $B$ is the largest primary care practice in the ACO network and provides health care services through 11 providers (6 physicians, 2 APRNs, 1 PA, and two residents). Other staff includes seven receptionists, 5 MAs, 1 CNA, 4 LPNs, 3 RNs, one clinical data specialist/coordinator, and one radiology technician. Both clinics have participated in developing distance-learning modules of participatory approach from September 2019 to October 2020.

\section{Study design}

This study was designed using the principles of participatory action research. It included reflection on a priority issue for practice partners (i.e., CRCS), collaborative data collection, and action to design acceptable and feasible implementation strategies to improve patient disease prevention. To assess the feasibility and acceptability of our co-produced bundle of implementation strategies, we used one group posttest- only design that incorporated quantitative and qualitative assessments.

\section{Study Participants}

Three to five representatives from each clinic participated in the study. Following guidance from the literature on systems-based approaches, we selected participants based on their roles within the clinical system (14). Each clinic had a designated 'primary care physician (PCP) champion,' accountable for leading local quality improvement (QI) efforts and engaging clinic staff in QI training/practice. The champions also had decision-making authority within the clinic related to CRCS EBI adoption and implementation and time and resources available to engage with the bundle of implementation strategies developed during the project. In addition to a champion with decision-making authority, we included clinic staff that would ultimately implement selected CRCS EBIs within the practice. This included nurses, clinical care coordinators, data specialists, or other administrative staff from each practice. The ACO leadership team (e.g., the director, clinical coordinator, and data/administrative staff) was also invited to, and engaged in, providing feedback on the process.

\section{Process of module development and delivery}

As illustrated in Fig. 1, we used the Plan-Do-Study-Act cycle as a key approach within our bundled implementation strategy. We conducted two qualitative focus groups to assess clinic representatives' opinions regarding the most suitable methods to receive information on EBI characteristics and blueprints for implementation, systems-change strategies to facilitate implementation, and tools to identify implementation strategies that are both efficient and effective. A number of methods were considered to guide the co-production of the bundle of implementation strategies, including synchronous (real-time) or asynchronous (time-lagged) communications, such as (1) online lecture, (2) online discussion board, (3) live stream video/audio group discussion, and/or (4) in-person discussion/feedback. To facilitate this process, an expert in distance education and instructional design worked with the team to develop the most acceptable and feasible approach to deliver the bundled 
implementation strategies. Our academic-clinical partnership adapted PPHEA program content to be delivered synchronously or asynchronously to all participating clinic members using selected learning platforms and methods. Upon completing each session ( $n=8$ sessions), participants provided feedback using surveys to assess perceptions of the bundled approach and potential adaptations for the next session.

\section{Evaluation plan and measures}

We administered an online survey asking participants' reactions after completing each module regarding (1) overall satisfaction, (2) knowledge enhancement, (3) relevance to the job, (4) time investment, and (5) credibility of information. We adapted the post-training evaluation measures in the PPHEA training guide (28). After completing the first and last module, we evaluated participants' perceptions of the bundled approach using Rogers' Innovation Characteristics Measures (Relative Advantage, Compatibility, Simplicity, Trialability, and Observability) after completing the first and last module (29). We adapted the questionnaires from the three existing studies (30-32). Relative Advantage is defined as the degree to which an innovation (the bundled approach) is perceived as being better than the idea it supersedes. An example of the item was "The bundled approach is better than our current approach of selecting implementing CRC screening interventions." Compatibility is the degree to which an innovation is perceived as consistent with the existing values, past experiences, and needs of potential adopters. An example item was "Using the bundled approach fits well the systems of care delivery in my organization." Simplicity refers to the degree to which an innovation is perceived as relatively easy to understand and use. For example, we included an item "Using the bundled approach was clear and understandable." Trialability refers to the degree to which an innovation may be experimented with on a limited basis. We included an item such as "Before deciding to take the full approach across my organization, I was able to try it out in a small scale properly." Observability is defined as the degree to which the results of an innovation are visible to others. An example item was "I would have no difficulty telling others about the benefit of using it." All items were rated on a 5-point Likert Scale of $1=$ Strongly Disagree to $5=$ Strongly Agree. Participants received a $\$ 10$ gift card for completing each survey and an additional $\$ 20$ gift card for completing all eight surveys. After all, sessions were delivered, an in-depth, 45-minute individual interview followed to ask participants' overall perceptions of the feasibility and acceptability of the bundled approach, module contents, logistics and suggestions for modification for the future trial.

\section{Analysis}

We used descriptive statistics, including Means, Standard Deviations, Frequencies, and Percentages, to analyze survey data. Focus groups/Interview data were analyzed by inductive and deductive development and organization of thematic codes. The research team developed a coding structure, which includes key conceptual domains and participant perspectives. Minor modifications were made iteratively until the model was saturated. Data were analyzed using SAS version 9.3 and NVivo qualitative analysis software (QSR NVivo 11).

\section{Results}




\section{Implementation Strategy Module Development}

The module development team consisted of an implementation scientist (PE), health services researcher (JK), distance-learning instructional designer (AM), and research assistant (AA). Based on participants' preferences on delivery mode identified through our initial focus group, the original eight sessions were converted to pre-recorded, online video sessions followed by online forums or live-streaming conference videos/calls facilitated by the module development team. Following the PPHEA training facilitator's guide, we included all core contents in each training session and customized contexts/supplemental materials (e.g., handouts or tools) specific to CRCS EBIs (see Table 1 for more detailed information on adaptation). We used two platforms for delivering sessions, web-based learning management software ('Moodle' system) and an email. 
Table 1

Adaptation of Putting Public Health Evidence in Action Curriculum

\begin{tabular}{ll} 
Topic & Original Contents \\
$\begin{array}{ll}\text { Session 1: } & \cdot 25 \text { minutes of interactive lecture with } \\
\text { Defining } & \text { PPT slides }\end{array}$ \\
\hline
\end{tabular}

evidence

Session 2:

Conducting

community

assessments
- 40 minutes of interactive lecture with PPT slides and activity (community assessment worksheet)

\section{Adaptation}

- Three, 6-minute video clips:

- Two online forums

-30-minute, live streaming conference video/call

- Three, 6-9-minute video clips

- Modify handouts specific to CRCS (community assessment template; problem logic map; list of resources; goals/objectives worksheet)

- An online forum

-30-minute, live streaming conference video/call

- Two 8-10-minute video clips

- Modify EBI resources specific to CRCS (e.g., CommunityGuide and RTIPS) hunt)

- Handouts (resource list, finding scavenger hunt answer key)

- Two online forums

-30-minute, live streaming conference video/call

- Two 8-10-minute video clips

- Modify EBI comparison tool to understand which EBI (e.g., patient navigator or Flu-FIT) is best fit for the individual clinical practice based on priorities and target population.

- An online forum

-30-minute, live streaming conference video/call

- Two 10-minute video clips

- Modify adaptation guidance tool using CRCS EBI examples

- Two online forums

-30-minute, live streaming conference video/call 


\begin{tabular}{|c|c|c|}
\hline Topic & Original Contents & Adaptation \\
\hline $\begin{array}{l}\text { Session 6: } \\
\text { Implementing } \\
\text { an EBI }\end{array}$ & $\begin{array}{l}\text { - } 60 \text { minutes of interactive lecture with } \\
\text { PPT slides and activity (PDSA cycle } \\
\text { activity) } \\
\text { - Handouts: Organizational readiness } \\
\text { checklist } \\
\text { - PDSA template } \\
\text { - Project charter template, workplan } \\
\text { template, example body and soul work } \\
\text { plan }\end{array}$ & $\begin{array}{l}\text { - Two 10-12 minutes video clips: } \\
\text { - Modify implementation team charter, } \\
\text { workplan template using CRCS EBI } \\
\text { example (e.g., Flu-FIT) } \\
\text { - An online forum } \\
\text { - } 30 \text {-minute, live streaming conference } \\
\text { video/call }\end{array}$ \\
\hline $\begin{array}{l}\text { Session 7: } \\
\text { Planning for } \\
\text { evaluation }\end{array}$ & $\begin{array}{l}\text { - } 35 \text { minutes of interactive lecture with } \\
\text { PPT slides and activity (planning for } \\
\text { evaluation activity; evaluation plan } \\
\text { template activity) } \\
\text { - Handouts: evaluation designs, } \\
\text { evaluation resource list; logic model } \\
\text { example Flu-FIT; Flu-FIT description, } \\
\text { Body and Soul description }\end{array}$ & $\begin{array}{l}\text { - Two 10-15-minute video clips: } \\
\text { - Modify evaluation plan and logic } \\
\text { model using CRCS examples (Flu-FIT, } \\
\text { small media) } \\
\text {-30-minute, live streaming conference } \\
\text { video/call }\end{array}$ \\
\hline $\begin{array}{l}\text { Session 8: } \\
\text { Creating a } \\
\text { communication } \\
\text { plan for EBI }\end{array}$ & $\begin{array}{l}\text { - } 35 \text { minutes of interactive lecture with } \\
\text { PPT slides and activity (safe routes to } \\
\text { school example) } \\
\text { - Handouts: communication plan } \\
\text { template; communication plan (blank) }\end{array}$ & $\begin{array}{l}\text { - One 14-minute video clip } \\
\text { - Modify a communication plan for the } \\
\text { CRCS EBI (Flu-FIT) to define goals, } \\
\text { objectives, audiences, marketing and } \\
\text { communication channels, and } \\
\text { timelines. } \\
\text { - An online forum } \\
\text { - } 30 \text {-minute, live streaming conference } \\
\text { video/call }\end{array}$ \\
\hline
\end{tabular}

\section{Clinic Team Characteristics and Learning styles}

The implementation strategy development team composition grew relatively organically within each clinic and differed for the two clinics. Clinic A team consists of primary care providers (2 physicians and 1 APRN) and a nurse clinical manager of translation hired by the ACO. Clinic B was somewhat more interdisciplinary and included a physician, a clinical data coordinator, an RN care coordinator, a referral/schedule coordinator, and a care manager.

The two clinical teams also showed different learning styles. Clinic A used a 'group learning' approach (viewed online lecture together). In contrast, Clinic B used a 'hybrid learning' approach (individuals viewed online lectures separately) to cover material before a group meeting and video conference facilitated by the academic partners.

\section{Module Delivery}


We originally planned to deliver all eight adapted modules monthly for the two clinics. However, after implementing the first module (EBI definition), Clinic A provided feedback regarding the video lecture presentation quality and content. Specifically, more examples of CRCS EBIs were requested. Further, Clinic A opted to skip the module on community assessment (Module 3 ) and move directly to the module on where to find EBIs (Module 4). Clinic B completed all eight sessions as planned (see Table 2).

Table 2

Original and Adapted Plan for Implementation Strategy Delivery

\begin{tabular}{|c|c|c|}
\hline & Original plan & Adaptation \\
\hline \multirow[t]{2}{*}{$\begin{array}{l}\text { Team } \\
\text { Composition }\end{array}$} & \multirow{2}{*}{$\begin{array}{l}\text { Having an interdisciplinary team } \\
\text { including decision-makers, } \\
\text { implementers, and support staff }\end{array}$} & $\begin{array}{l}\text { - Clinic A team included providers only (2MDs } \\
\text { and } 1 \text { PA) except a care manager from ACO. }\end{array}$ \\
\hline & & $\begin{array}{l}\text { - Clinic B team was more interdisciplinary (1 lead } \\
\text { physician, } 1 \text { clinical data coordinator, } 1 \mathrm{RN} \text { care } \\
\text { coordinator, } 1 \text { referral/scheduling coordinator, } 1 \\
\text { care manager) }\end{array}$ \\
\hline \multirow[t]{2}{*}{ Format } & \multirow{2}{*}{$\begin{array}{l}15-20 \text {-minute video lecture } \\
\text { followed by } 30 \text {-minute live- } \\
\text { streaming conference call/video } \\
\text { through learning management } \\
\text { system (LMS) }\end{array}$} & $\begin{array}{l}\text { - Clinic A prefers to receive information (video } \\
\text { links and surveys) via email rather than using } \\
\text { web based LMS. }\end{array}$ \\
\hline & & - Clinic B adopted LMS. \\
\hline \multirow[t]{2}{*}{$\begin{array}{l}\text { Learning } \\
\text { approach }\end{array}$} & \multirow{2}{*}{$\begin{array}{l}\text { Participants are expected to } \\
\text { watch video individually and } \\
\text { come to live-streaming session } \\
\text { for group discussion. }\end{array}$} & $\begin{array}{l}\text { - Clinic A prefers to watch the video together } \\
\text { followed by group discussion in a reserved } \\
\text { conference room. }\end{array}$ \\
\hline & & $\begin{array}{l}\text { - Clinic B prefers to watch lecture video } \\
\text { individually followed by group discussion via } \\
\text { live-streaming conference }\end{array}$ \\
\hline \multirow[t]{3}{*}{ Delivery } & $\begin{array}{l}\text { Deliver all } 8 \text { sessions in a } \\
\text { monthly interval. }\end{array}$ & \multirow{2}{*}{$\begin{array}{l}\text { - Clinic A: } 7 \text { sessions were delivered (Skipped } \\
\text { session } 2 \text { after receiving feedback from the } 1 \text { st } \\
\text { session that they would like to minimize basic } \\
\text { definition parts and jump right into the EBI } \\
\text { examples). }\end{array}$} \\
\hline & \multirow{2}{*}{$\begin{array}{l}\text { Weekly reminder to complete } \\
\text { video lecture prior to live- } \\
\text { streaming sessions }\end{array}$} & \\
\hline & & $\begin{array}{l}\text { - Clinic B: All } 8 \text { sessions were delivered as } \\
\text { planned. Due to COVID-19 last two sessions were } \\
\text { postponed. }\end{array}$ \\
\hline
\end{tabular}

\section{Participants' Reactions}

Across all sessions, participants in both Clinic A and B reported high mean scores on overall satisfaction, knowledge enhancement, relevance to job, worth the time invested, and credibility of information (See Table 3). 
Table 3

Participants' Reaction to the Implementation Strategy

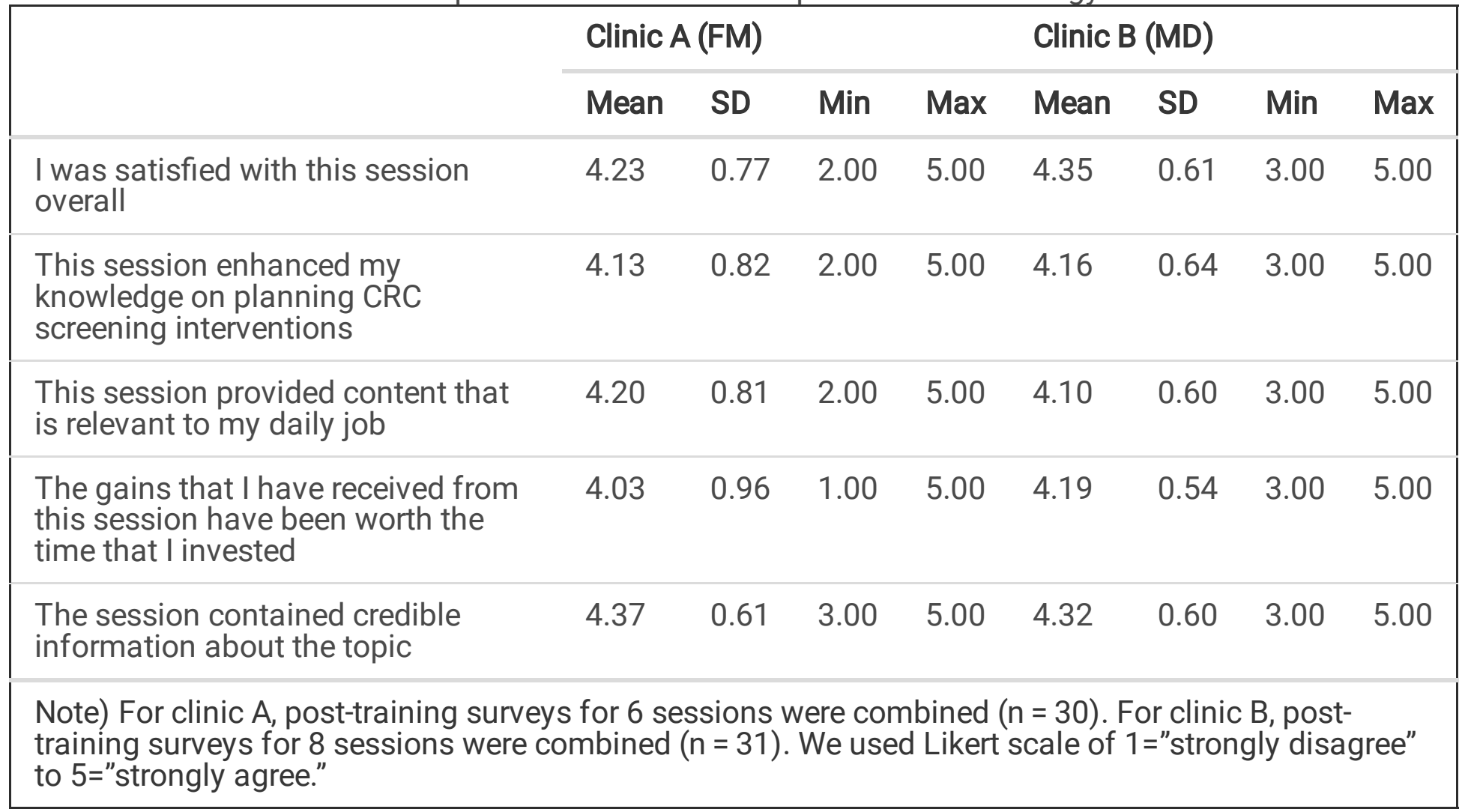

\section{Implementation Strategy Characteristics}

Both clinics reported improvements in their perceptions of the implementation strategy (i.e., innovation) after completing the training, although differences vary by characteristic domain and clinic. In Clinics A and $B$, the largest improvements were shown in relative advantage. Clinic $A$ also indicated improvements in trialability, while in Clinic B, improvements were also seen in compatibility (See Table 4). 
Table 4

Participants' Perceptions toward Innovation Characteristics (Before and After)

\begin{tabular}{|lllll|}
\hline \multicolumn{4}{|c|}{ Clinic A } & \multicolumn{3}{c|}{ Clinic B } \\
\hline & $\begin{array}{l}\text { Baseline } \\
(\mathrm{n}=7)\end{array}$ & $\begin{array}{l}\text { Follow-up } \\
(\mathrm{n}=3)\end{array}$ & $\begin{array}{l}\text { Baseline } \\
(\mathrm{n}=4)\end{array}$ & $\begin{array}{l}\text { Follow-up } \\
(\mathrm{n}=3)\end{array}$ \\
\hline Relative advantage & 3.00 & 4.43 & 3.86 & 4.52 \\
\hline Compatibility & 4.00 & 4.40 & 3.95 & 4.67 \\
\hline Simplicity & 3.19 & 4.50 & 4.25 & 4.56 \\
\hline Trialability & 3.33 & 4.67 & 4.17 & 4.33 \\
\hline Observability & 3.42 & 4.44 & 4.00 & 4.11 \\
\hline $\begin{array}{l}\text { Note) We measured these items after the first session (baseline) and after the last session (follow- } \\
\text { up). We used Likert scale of } 1=\text { "strongly disagree" to 5="strongly agree." }\end{array}$ & \\
\hline
\end{tabular}

\section{Specific Plans to Implement EBIs}

After completing all the modules, both clinics developed a specific plan to implement CRCS EBIs. Clinic A chose a small media intervention using mailed postcards to remind patients regarding CRCS followed by telephone reminders. Clinic B developed an idea to adapt Flu-FIT, which uses an injection nurse to recommend CRCS for patients who visit the clinic for receiving the flu vaccine.

\section{Qualitative Feedback from Post-Training Interview}

As illustrated in Table 5, participants generally reported that the participatory approach to develop a bundle of implementation strategies through monthly sessions was acceptable and appropriate for rural practice. Participants felt that EBI video content was relevant and easy to understand, but some parts were redundant. One participant (Director of Care Coordination) said: "I just think there was a little bit of redundancy through each one. It felt like we were restarting from the beginning. But otherwise, I think they were good." 
Table 5

Results from Post-Training Interview

\begin{tabular}{|c|c|c|c|}
\hline & Theme & Description & Example quotes \\
\hline $\begin{array}{l}\text { Overall } \\
\text { approach }\end{array}$ & Appropriateness & $\begin{array}{l}\text { Appropriate for rural practice, } \\
\text { acceptable, helpful and } \\
\text { educational }\end{array}$ & $\begin{array}{l}\text { "I think it would be a great tool } \\
\text { for our rural areas; that don't } \\
\text { have that opportunity to get their } \\
\text { numbers up or are not aware } \\
\text { of the importance of that and } \\
\text { trying to get their numbers up in } \\
\text { the colorectal cancer screening. I } \\
\text { thought they were well presented } \\
\text { and, were very well done." - } \\
\text { Referral coordinator. }\end{array}$ \\
\hline \multirow[t]{2}{*}{$\begin{array}{l}\text { Video } \\
\text { contents } \\
\text { and } \\
\text { presentation }\end{array}$} & Video content & $\begin{array}{l}\text { Relevant and easy to } \\
\text { understand; but some parts } \\
\text { were redundant }\end{array}$ & $\begin{array}{l}\text { "The presentations as far as } \\
\text { walking us through the videos } \\
\text { and the information that you } \\
\text { provided, it was all relevant and } \\
\text { easy to understand" - Certified } \\
\text { case manager. }\end{array}$ \\
\hline & $\begin{array}{l}\text { Video } \\
\text { presentation }\end{array}$ & $\begin{array}{l}\text { Tone was too monotonous, } \\
\text { but improved after initial } \\
\text { feedback }\end{array}$ & $\begin{array}{l}\text { "The voiceover in the video, the } \\
\text { monologue, was difficult to } \\
\text { follow. But, after we gave you } \\
\text { guys that feedback, since that } \\
\text { time they've all been great" - } \\
\text { Certified case manager. }\end{array}$ \\
\hline \multirow[t]{2}{*}{$\begin{array}{l}\text { Live- } \\
\text { streaming } \\
\text { conference }\end{array}$} & Conversation & $\begin{array}{l}\text { Initiate's conversation } \\
\text { relevant to CRC screening; } \\
\text { Beneficial to touch base with } \\
\text { others (providers/staff at } \\
\text { clinic) }\end{array}$ & $\begin{array}{l}\text { "I like that we do the } \\
\text { conversation afterwards } \\
\text { because, you know, even if we } \\
\text { don't necessarily talk about } \\
\text { everything that we learned in the } \\
\text { video, it often sparked } \\
\text { conversation relevant" - Certified } \\
\text { case manager. }\end{array}$ \\
\hline & facilitation & $\begin{array}{l}\text { Good } \\
\text { facilitation/feedback/support } \\
\text { from research team }\end{array}$ & $\begin{array}{l}\text { "I think that they were helpful. It's } \\
\text { nice to get feedback on what } \\
\text { you have discussed amongst } \\
\text { your own group with - with } \\
\text { other people. And I think that's a } \\
\text { good thing to do" - Referral } \\
\text { coordinator }\end{array}$ \\
\hline $\begin{array}{l}\text { Tools/ } \\
\text { resources }\end{array}$ & Usefulness & $\begin{array}{l}\text { Template, websites, and } \\
\text { handouts were useful }\end{array}$ & $\begin{array}{l}\text { "I really liked those handouts } \\
\text { that were attached to the portal. } \\
\text { Those different Websites were } \\
\text { great. You know, something that } \\
\text { we weren't using before" - } \\
\text { Director of Care Coordination }\end{array}$ \\
\hline
\end{tabular}




\begin{tabular}{|c|c|c|c|}
\hline & Theme & Description & Example quotes \\
\hline & Adaptability & $\begin{array}{l}\text { Templates were easily } \\
\text { modified/compatible by } \\
\text { clinic teams }\end{array}$ & $\begin{array}{l}\text { "The templates and stuff were } \\
\text { really helpful. We could print } \\
\text { those off and come up with a } \\
\text { plan that we thought would work } \\
\text { and then present it and see } \\
\text { what your thoughts were" - } \\
\text { Referral coordinator }\end{array}$ \\
\hline \multirow[t]{3}{*}{ Format } & $\begin{array}{l}\text { Provider } \\
\text { participation }\end{array}$ & $\begin{array}{l}\text { Having providers } \\
\text { (MDs/PAs/NPs) in the team } \\
\text { was helpful to get buy-in's, } \\
\text { actions followed, and } \\
\text { feedback on feasibility and } \\
\text { resources }\end{array}$ & $\begin{array}{l}\text { "Having the opportunity to talk } \\
\text { to the providers and getting their } \\
\text { feedback of what's going to } \\
\text { work and what's not going to } \\
\text { work, what's realistic in real-life } \\
\text { practice and just hearing their } \\
\text { side of what resources and tools } \\
\text { they might need" - Certified case } \\
\text { manager. }\end{array}$ \\
\hline & $\begin{array}{l}\text { Monthly } \\
\text { session }\end{array}$ & $\begin{array}{l}\text { Monthly interval was } \\
\text { appropriate, and helps keep } \\
\text { the conversations going; }\end{array}$ & $\begin{array}{l}\text { "I think for us in this office, the } \\
\text { monthly was the best way to do } \\
\text { it" - Referral coordinator. }\end{array}$ \\
\hline & & helpful & $\begin{array}{l}\text { "Just the fact that we are taking } \\
\text { the time out of our schedule to } \\
\text { talk about it and brainstorm } \\
\text { ways to do things, I think that } \\
\text { was a great benefit." - Certified } \\
\text { case manager. }\end{array}$ \\
\hline \multirow[t]{3}{*}{ Delivery } & $\begin{array}{l}\text { Learning } \\
\text { management } \\
\text { system }\end{array}$ & $\begin{array}{l}\text { Half of the participants } \\
\text { adopted the software; the } \\
\text { other half preferred email; } \\
\text { online discussion board was } \\
\text { not used by all participants }\end{array}$ & $\begin{array}{l}\text { "I did not like the } \\
\text { discussion boards. I didn't feel } \\
\text { like they were very helpful to } \\
\text { me."-Director of care } \\
\text { coordination }\end{array}$ \\
\hline & & & $\begin{array}{l}\text { "I think having sent out the } \\
\text { specific links was great because, } \\
\text { you get busy, and you're like, I } \\
\text { don't remember where we are } \\
\text { at?" - Certified case manager }\end{array}$ \\
\hline & Reminder & $\begin{array}{l}\text { Weekly reminder was helpful } \\
\text { for individual learning }\end{array}$ & $\begin{array}{l}\text { "I thought that was a good } \\
\text { format. Sometimes I would get } \\
\text { busy and forget about them. So } \\
\text { the weekly reminders were really } \\
\text { helpful" - Referral coordinator }\end{array}$ \\
\hline
\end{tabular}




\begin{tabular}{|c|c|c|c|}
\hline & Theme & Description & Example quotes \\
\hline & Scheduling & $\begin{array}{l}\text { scheduling for live } \\
\text { conference was challenging }\end{array}$ & $\begin{array}{l}\text { "I think the main challenge that I } \\
\text { guess I had was just } \\
\text { getting everybody's work } \\
\text { schedules to work and getting } \\
\text { everybody to respond back. I } \\
\text { know we had sometimes where } \\
\text { it's like, I'm trying to get this on } \\
\text { the schedule, but it's not } \\
\text { working" - Certified case } \\
\text { manager }\end{array}$ \\
\hline \multirow[t]{6}{*}{ Suggestions } & \multirow{4}{*}{$\begin{array}{l}\text { Discrepancy } \\
\text { about potential } \\
\text { participants for } \\
\text { future training }\end{array}$} & $\begin{array}{l}\text { Only providers should be } \\
\text { involved, and other staff can } \\
\text { be included occasionally }\end{array}$ & $\begin{array}{l}\text { "I think just having the providers } \\
\text { there is the best."- Certified case } \\
\text { manager }\end{array}$ \\
\hline & & $\begin{array}{l}\text { Nurses, scheduling staff, } \\
\text { chronic care management } \\
\text { team should be included; MA } \\
\text { and CNAs should be } \\
\text { involved. }\end{array}$ & $\begin{array}{l}\text { "I really think it starts with just } \\
\text { the demeanor of the front } \\
\text { staff checking them in. You } \\
\text { know, maybe giving them a } \\
\text { handout or starting } \\
\text { that conversation }\end{array}$ \\
\hline & & & $\begin{array}{l}\text { comes way before that doctor" - } \\
\text { Director of care coordination. }\end{array}$ \\
\hline & & & $\begin{array}{l}\text { "I'd like to see the bulk of the } \\
\text { nurses trained to use them. But } \\
\text { right now, I'd like to really see } \\
\text { the chronic care managers get } \\
\text { involved and use them" - } \\
\text { Physician. }\end{array}$ \\
\hline & $\begin{array}{l}\text { Improvements } \\
\text { in delivery }\end{array}$ & $\begin{array}{l}\text { Sending information in } \\
\text { advance; removing online } \\
\text { discussion board unless } \\
\text { more interactive }\end{array}$ & $\begin{array}{l}\text { "The only other suggestion I } \\
\text { would have is maybe send out - } \\
\text { if we do a month apart on the } \\
\text { modules, maybe send the } \\
\text { modules out maybe two weeks } \\
\text { in advance or a little bit earlier } \\
\text { just to have time just in case you } \\
\text { have downtime at the clinic to } \\
\text { watch it." - Certified case } \\
\text { manager }\end{array}$ \\
\hline & $\begin{array}{l}\text { Improvements } \\
\text { in video content }\end{array}$ & $\begin{array}{l}\text { remove redundancy from the } \\
\text { video lecture (e.g., basic } \\
\text { definitions, repeated } \\
\text { examples of EBIs) }\end{array}$ & $\begin{array}{l}\text { "The only thing would } \\
\text { be making it a little less; the } \\
\text { nurses did complain that it was } \\
\text { a little redundant." - Physician }\end{array}$ \\
\hline
\end{tabular}

Along with video lectures, participants seemed to enjoy the follow-up discussion through live-streaming video conferences. Participants said that the live streaming session was helpful to keep the conversation going within their team but also helpful by receiving feedback and additional support (e.g., resources) from the research team. Participants reported positive feedback about templates or handouts provided by 
each session. They mentioned that these templates were very helpful for selecting the right EBI program and easy to modify given their clinic context.

Regarding implementation strategy format and process of co-production, participants indicated that having providers (MDs, PAs/NPs) on the team was helpful because it gained buy-ins and led to system changes to address actions needed for CRCS implementation. Participants found the monthly interval appropriate for recurring sessions and provided time to enact strategies and systems change needed between sessions. There were clinical differences in the learning platform preferences-one clinic adopted and used the Moodle system that allowed for more self-direction and easy, one-stop-shop for accessing implementation materials, while the other preferred receiving the strategy via email. A participant (Certified Case Manager) said: "I think having sent out the specific links was, great because, you know, you get busy, and you're like, I don't remember what - where are we at? What are we supposed to be looking at?"

We asked participants' suggestions for future implementation strategies in terms of who should be involved and how the strategy could be improved. One group thought providers should be involved mainly, and the other group suggested including other staff, like nurses, scheduling staff, or care managers. In terms of delivery and contents, participants suggested removing redundant parts from the lecture (e.g., definitions or repeated use of the same EBI examples) and remove/modify online discussion boards.

\section{Discussion}

The selection and implementation of CRCS screening EBIs in rural primary care clinics are critical given the geographic disparities in cancer screening and outcomes. Equally important is understanding how these clinics perceive implementation strategies intended to facilitate the uptake of CRCS EBIs. In this study, we began our approach using the PPHEA modules that provide training and education for professionals interested in identifying, adapting, and implementing EBls (28). Our project provides preliminary information about the potential of a distance-learning version of this implementation strategy for rural primary care clinics. We also used a participatory approach to make iterative changes to the implementation strategy based on clinic staff feedback. In sum, we found that the implementation strategy is feasible and acceptable in rural primary care practices.

While this is preliminary and pilot from 2 rural clinics, our findings align with research that suggests the likely success of implementation strategies that bundle activities such as academic-clinic partnerships, developing a blueprint for implementation, quality improvement strategies, and regular feedback with iterative adaptations (17). Indeed, aligning with the desire for having packaged programs and intervention content readily accessible, early feedback from clinics highlighted strong interest in having specific CRC evidence-based intervention examples. This resulted in the integration of $6 \mathrm{EBI}$ strategies recommended by the CommunityGuide (small media, client reminder, one-on-one education, provider feedback and assessment, and provider reminder, reducing structural barriers) and three packaged programs introduced 
by Research Tested Intervention Programs (Flu-FIT/FOBT, Community Cancer Screening Program, and FIT \& Colonoscopy Outreach). In addition, participants reported that the use of handouts and templates provided by the modules were helpful and easy to develop their ideas as a group.

While only a pilot, the process supported both clinics in identifying and initiating implementation of evidence-based approaches to increase CRC screening. Both clinics selected evidence-based

interventions that had been included as examples, underscoring the need to do preliminary work to ensure that a range of examples are provided to fit differential resources across rural clinics.

Of course, as a pilot project, there are a number of limitations. These include a small sample of clinics and staff from each clinic, and both clinics also came from the same region, which limits generalizability. Finally, our quantitative data is limited to descriptive considerations rather than inferential statistics due to the small sample size. Nevertheless, our qualitative data indicated that this participatory approach fits well with the clinical resources, time, and interest. Future work will include testing the newly developed modules in a broader range of rural clinics to determine the utility in supporting evidence-based intervention selection, adoption, implementation, and sustainability through a participatory approach.

\section{Conclusions}

Little is known about the co-production of implementation strategies for evidence-based CRCS in rural primary care clinics. We used a bundle of strategies (developing an academic-clinical partnership, forming an electronic blueprint, implementing quality improvement strategies, and providing regular feedback and iterative adaptations) to help rural clinics identify the best fitting EBI to their practice context. We developed eight systems-change modules to build an electronic blueprint for CRCS EBI selection and implementation combined with monthly online forums or live-streaming conferences to allow for CRCS tailoring. After completing all the modules, participants in two rural clinics reported positive reactions toward the systems-change modules. Both clinics reported improvements in how they perceived the characteristics of the modules and the participatory approach to tailor selected CRCS EBIs. Through the process, both clinics developed a specific EBI implementation plan. Our preliminary data showed that our bundle of implementation strategies used were feasible and acceptable in rural primary care practices to facilitate the use of evidence-based approaches to improve CRCS.

\section{Abbreviations}

ACO Accountable Care Organization

APRN Advance Practice Registered Nurse

BCBS Blue Cross Blue Shield

CNA Certified Nursing Assistant

Page $17 / 22$ 
CRC Colo-Rectal Cancer

CRCS Colo-Rectal Cancer Screening

CPCRN Cancer Prevention and Control Research Network

EBI Evidence Based Intervention

EMR Electronic Medical Records

LPN Licensed Practical Nurse

MA Medical Associate

PA Physician Assistant

PCP Primary Care Physician

PDSA Plan-Do-Study-Act

PPHEA Putting Public Health Evidence in Action

QI Quality Improvement

RN Registered Nurse

USPSTF United States Preventive Services Task Force

\section{Declarations}

- Ethics approval and consent to participate.

The study was approved by University of Nebraska Medical Center Institutional Review Board (IRB \# 22719-EP)

- Consent for publication

The University of Nebraska Medical Center Institutional Review Board waived the consent form for the study.

- Availability of data and materials

The datasets used and/or analyzed during the current study are available from the corresponding author on reasonable request.

- Competing interests 
The authors declare that they have no competing interests.

- Funding

The study was funded by the Great Plains IDeA CTR pilot grant through the University of Nebraska Medical Center (UNMC), supported by National Institute of General Medical Sciences (1 U54 GM115458). The study was also funded by College of Public Health at the University of Nebraska Medical Center. The funding source had no role in the design, conduct, or reporting of the study or in the decision to submit the article for publication.

- Authors' contributions

JK conceptualized the study, delivered implementation strategies, analyzed and interpreted the data, and was a major contributor in writing the manuscript. PE provided mentorship of the study, delivered implementation strategies, and critically reviewed and revised the manuscript. AA coordinated delivery sessions, developed materials, collected, and analyzed data. AM contributed to the development of distance learning modules of implementation strategies. KA analyzed and interpreted survey data regarding participants' reactions and perceptions toward implementation strategies. All authors read and approved the final manuscript.

- Acknowledgements

We acknowledge our rural practice partners who selflessly and tirelessly work for improvement of health and well-being for rural residents.

- Authors' information (optional)

Jungyoon Kimreceived her PhD in Health Policy and Administration at the Pennsylvania State University. Currently, Dr. Kim is an Assistant Professor in the Department of Health Services Research and Administration at the University of Nebraska Medical Center, College of Public Health. Her research interests include organizational and system level change in healthcare and public health settings, particularly regarding the adoption and implementation of new policies or evidence-based practices.

\section{References}

1. Whitlock EP, Lin JS, Liles E, Beil TL, Fu R. Screening for colorectal cancer: a targeted, updated systematic review for the US Preventive Services Task Force. Ann Intern Med 2008 Nov 4;149(9):638-658.

2. American Cancer Society. Cancer Facts \& Figures. 2020.

3. Brouwers MC, De Vito C, Bahirathan L, Carol A, Carroll JC, Cotterchio M, et al. Effective interventions to facilitate the uptake of breast, cervical and colorectal cancer screening: an implementation guideline. Implementation Science. 2011;6(1):112. 
4. Sabatino SA, Lawrence B, Elder R, Mercer SL, Wilson KM, DeVinney B, et al. Effectiveness of interventions to increase screening for breast, cervical, and colorectal cancers: nine updated systematic reviews for the guide to community preventive services. Am J Prev Med. 2012 Jul;43(1):97-118.

5. Davis MM, Freeman M, Shannon J, Coronado GD, Stange KC, Guise J, et al. A systematic review of clinic and community intervention to increase fecal testing for colorectal cancer in rural and lowincome populations in the United States-How, what and when? BMC Cancer. 2018;18(1):40.

6. Community Preventive Services Task Force. Updated recommendations for client- and provideroriented interventions to increase breast, cervical, and colorectal cancer screening. Am J Prev Med. 2012 Jul;43(1):92-6.

7. Research Tested Intervention Programs (RTIPs). 2018; Available at: https://rtips.cancer.gov/rtips/programSearch.do.

8. Harden SM, Steketee A, Glasgow T, Glasgow RE, Estabrooks PA. Suggestions for advancing pragmatic solutions for dissemination: Potential updates to evidence-based repositories. American Journal of Health Promotion. 2021;35(2):289-94.

9. Powell BJ, Proctor EK, Glisson CA, Kohl PL, Raghavan R, Brownson RC, et al. A mixed methods multiple case study of implementation as usual in children's social service organizations: study protocol. Implementation Science. 2013;8(1):92.

10. Baker R, Camosso-Stefinovic J, Gillies C, Shaw EJ, Cheater F, Flottorp S, et al. Tailored interventions to address determinants of practice. Cochrane Database of Systematic Reviews 2015(4).

11. Davis TC, Rademaker A, Bailey SC, Platt D, Esparza J, Wolf MS, et al. Contrasts in rural and urban barriers to colorectal cancer screening. Am J Health Behav. 2013 May;37(3):289-98.

12. Cole AM, Jackson JE, Doescher M. Colorectal cancer screening disparities for rural minorities in the United States. J Prim Care Community Health 2013 Apr 1;4(2):106-111.

13. Carmichael H, Cowan M, Mclntyre R, Velopulos C. Disparities in colorectal cancer mortality for rural populations in the United States: Does screening matter? The American Journal of Surgery. 2020;219(6):988-92.

14. Estabrooks PA, Harden SM, Almeida FA, Hill JL, Johnson SB, Porter GC, et al. Using Integrated Research-Practice Partnerships to Move Evidence-Based Principles Into Practice. Exerc Sport Sci Rev. 2019 Jul;47(3):176-87.

15. Wolfenden L, Yoong SL, Williams CM, Grimshaw J, Durrheim DN, Gillham K, et al. Embedding researchers in health service organizations improves research translation and health service performance: the Australian Hunter New England Population Health example. J Clin Epidemiol. 2017;85:3.

16. Ramanadhan S, Davis MM, Armstrong R, Baquero B, Ko LK, Leng JC, et al. Participatory implementation science to increase the impact of evidence-based cancer prevention and control. Cancer Causes Control. 2018;29(3):363-9. 
17. Powell BJ, Waltz TJ, Chinman MJ, Damschroder LJ, Smith JL, Matthieu MM, et al. A refined compilation of implementation strategies: results from the Expert Recommendations for Implementing Change (ERIC) project. Implementation Science. 2015;10(1):1-14.

18. Thompson JH, Davis MM, Leo MC, Schneider JL, Smith DH, Petrik AF, et al. Participatory Research to Advance Colon Cancer Prevention (PROMPT): Study protocol for a pragmatic trial. Contemp Clin Trials 2018 Apr;67:11-15.

19. James AS, Filippi MK, Pacheco CM, Cully L, Perdue D, Choi WS, et al. Barriers to colorectal cancer screening among American Indian men aged 50 or older, Kansas and Missouri, 2006-2008. Prev Chronic Dis. 2013 Oct;3:10:E170.

20. Smith SA, Ansa BE, Sheats JQ, Hamilton SJ, Whitehead MS. Participatory Process for Implementing a Colorectal Cancer Screening Intervention: An Action Plan for Local Intervention Sustainability. 2015.

21. Cancer Prevention and Control Research Network. Putting Public Health Evidence in Action Training Curriculum. 2017; Available at: http://cpcrn.org/pub/evidence-in-action/. Accessed September/2, 2018.

22. Mainor AG, Decosimo K, Escoffrey C, Farris P, Shannon J, Winters-Stone K, et al. Scaling Up and Tailoring the "Putting Public Health in Action" Training Curriculum. Health promotion practice 2017:1524839917741486.

23. Boyle L, Homer M. Using what works: Adapting evidence-based programs to fit your needs. National Cancer Institute; 2006.

24. Leeman J, Blitstein JL, Goetz J, Moore A, Tessman N, Wiecha JL. Developing a Tool to Assess the Capacity of Out-of-School Time Program Providers to Implement Policy, Systems, and Environmental Change. Prev Chronic Dis 2016 Aug 11;13:E105.

25. Escoffery C, Carvalho M, Kegler MC. Evaluation of the prevention programs that work curriculum to teach use of public health evidence to community practitioners. Health Promot Pract. 2012;13(5):707-15.

26. Vanderpool RC, Gainor SJ, Conn ME, Spencer C, Allen AR, Kennedy S. Adapting and implementing evidence-based cancer education interventions in rural Appalachia: real world experiences and challenges. Rural Remote Health. 2011;11(4):1807.

27. Sabatino SA, Habarta N, Baron RC, Coates RJ, Rimer BK, Kerner J, et al. Interventions to increase recommendation and delivery of screening for breast, cervical, and colorectal cancers by healthcare providers systematic reviews of provider assessment and feedback and provider incentives. Am J Prev Med 2008 Jul;35(1 Suppl):S67-74.

28. Cancer Prevention and Control Research Network. 'Putting Public Health Evidence in Action' Training Workshop. 2017; Available at: https://cpcrn.org/old_training, 2021.

29. Rogers EM. Diffusion of innovations. Simon and Schuster; 2010.

30. Martins CB, Steil AV, Todesco JL. Factors influencing the adoption of the Internet as a teaching tool at foreign language schools. Comput Educ. 2004;42(4):353-74. 
31. Atkinson NL. Developing a questionnaire to measure perceived attributes of eHealth innovations. Am J Health Behav. 2007;31(6):612-21.

32. Moore GC, Benbasat I. Development of an instrument to measure the perceptions of adopting an information technology innovation. Information systems research. 1991;2(3):192-222.

\section{Figures}

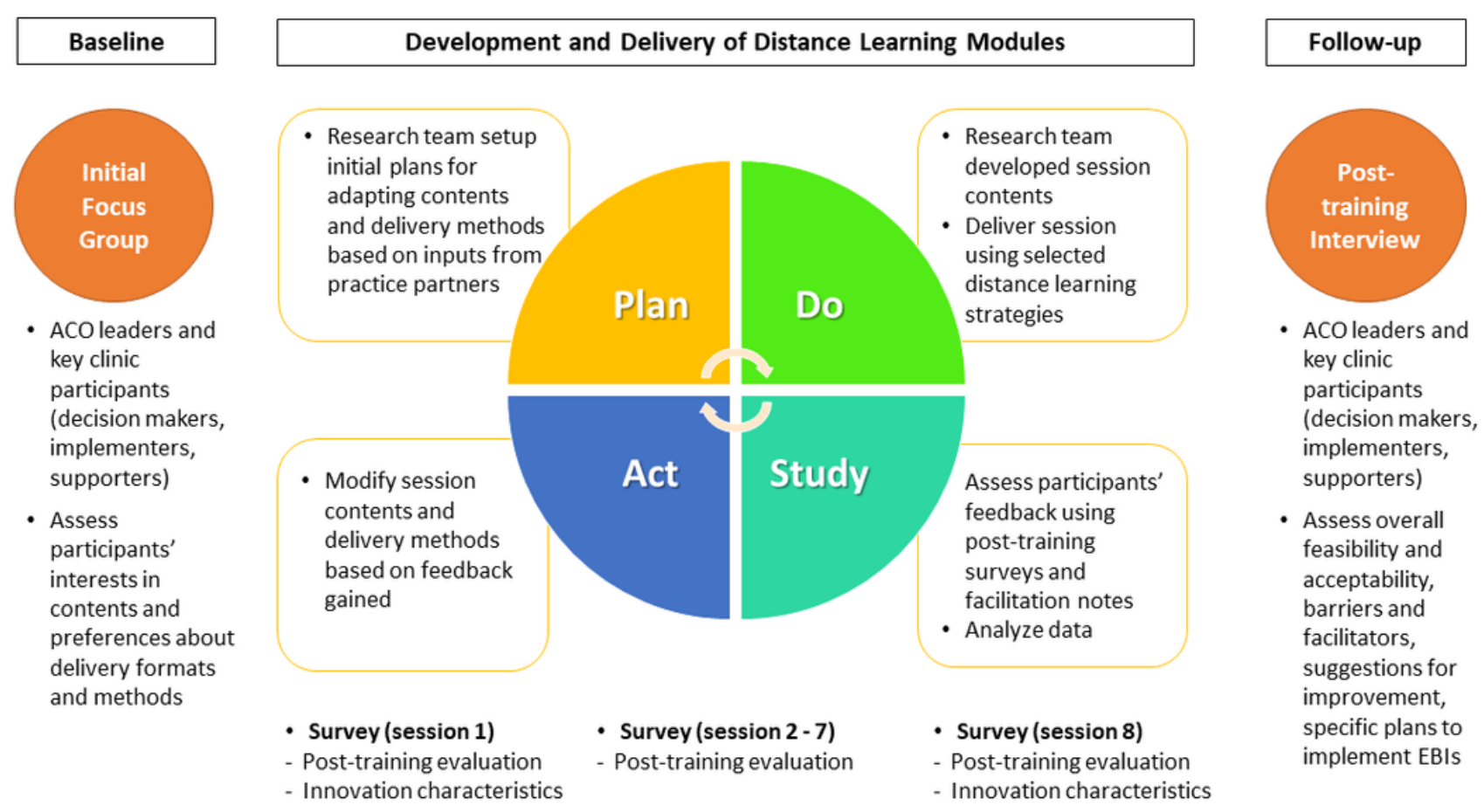

Figure 1

Process for Development and Application of Bundled Implementation strategies

\section{Supplementary Files}

This is a list of supplementary files associated with this preprint. Click to download.

- SupplementaryTable1.docx

- TIDieRChecklistWordFinal.docx 